\title{
Surgical and functional outcomes of radical retropubic prostatectomy after biopsy-related acute prostatitis
}

\author{
Şükrü Kumsar ${ }^{1}$, Emre Karabay², Omer Yüksel², Feridun Şengör ${ }^{2}$ \\ ${ }^{1}$ Baskent University istanbul Hospital, Department of Urology, Istanbul, Turkey \\ ${ }^{2}$ TC Saglik Bakanligi Haydarpasa Numune Egitim ve Arastirma Hastanesi, Department of Urology, Istanbul, Turkey
}

\begin{abstract}
Citation: Kumsar S, Karabay E, Yüksel O, Şengör F. Surgical and functional outcomes of radical retropubic prostatectomy after biopsy-related acute prostatitis. Cent European J Urol. 2019; 72: 19-22.
\end{abstract}

Article history

Submitted: Nov. 27, 2018

Accepted: Jan. 20, 2019

Published online: Jan. 22, 2019

Corresponding author Şükrü Kumsar Baskent University İstanbul Hospital Department of Urology 7 Oymacı Sokak

34662 Altunizade/Istanbul Turkey

phone: +90 5056778852

drkumsar@yahoo.com
Introduction The present study sought to evaluate the intraoperative, postoperative, oncologic, and functional results of radical prostatectomy (RP) after previous prostatitis.

Material and methods We retrospectively reviewed available data of 320 patients undergoing open radical prostatectomy between 2010 and 2016. From this group, 23 (7.2\%) had previous transrectal prostate biopsy-related acute prostatitis history. The perioperative and postoperative data were statistically compared between Group 1 (with previous prostatitis) and Group 2 (without previous prostatitis). The variables that were evaluated included demographic characteristics, perioperative complications, functional and oncological outcomes.

Results In Group 1, the operative time, hospitalization and bladder catheterization time was statistically increased by 40 min, 1.9 days, and 2.5 days, respectively $(p<0.001, p<0.001, p=0.02)$. The positive margin rate was not significantly different between the two groups $(p=0.64)$. The rate of complications with Clavien >2 increased in Group 1 (G1 26\% vs. G2 12\%) ( $p=0.02$ ). Neurovascular bundle preservation ratio was statistically higher in Group 2 (G1 46.5\% vs. G2 76.9\%) ( $p=0.02$ ). The functional results were similar for both groups 12 months after surgery.

Conclusions Previously, transrectal prostate biopsy-related acute prostatitis history was associated with a higher operative time, hospitalization and bladder catheterization time, and perioperative complications during RP. According to our study, although the neurovascular bundle preservation is technically more difficult, potency and urinary continence rate was not affected by previous prostatitis history. However, further studies are still required to confirm these results.

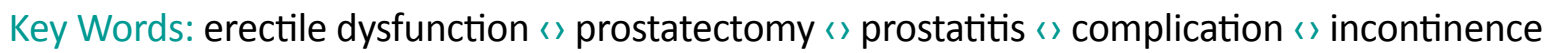

\section{INTRODUCTION}

Acute bacterial prostatitis is an acute infection of the prostate gland that can cause systemic symptoms (fever, chills, malaise, nausea and vomiting) and voiding symptoms (dysuria, voiding difficulty, increased urinary frequency and urgency) [1,2]. Most cases can be diagnosed with a convincing history and physical examination [3]. Generally, acute bacterial prostatitis is caused by an ascending urethral infection or intraprostatic reflux $[4,5,6]$. Most of these infections may occur from direct inoculation after transrectal prostate biopsy and transurethral manipulations [7]. Direct or lymphatic spread from the rectum or hematogenous spread via bacterial sepsis can cause acute bacterial prostatitis [8]. For diagnosing prostate cancer $(\mathrm{PCa})$, transrectal ultrasound-guided prostate biopsy (TRUS-TRBx) is generally accepted as a standard procedure [9].

However, despite their large application, TRUS biopsies are associated with higher rates of post-biopsy infections and sepsis because of rectal mucosa 
multi-resistant bacteria inoculation within the urinary tract [10].

The incidence of acute bacterial prostatitis (ABP) because of TRBx (Bx-ABP) has increased in the last 10 years, possibly because of an increase in the quinolone-resistant Escherichia coli in the community $[11,12,13]$.

The impact of prostate biopsies and their possible complications on the prostate surrounding tissues has attracted considerable interest. However, there is still no evidence in the literature that demonstrates whether previous biopsy-related prostatitis history can have an impact on an eventual radical prostatectomy.

In this study, we aimed to investigate and compare the morbidity and functional results after radical retropubic prostatectomy with and without previous transrectal prostate biopsy-related acute prostatitis history.

\section{MATERIAL AND METHODS}

From May 2010 to June 2016, 320 patients underwent open radical retropubic prostatectomy, from which $23(7.2 \%)$ had previous transrectal prostate biopsy-related acute prostatitis history and were thus included for this study. The patients who had repeated biopsy history were excluded.

Acute prostatitis diagnosis was made after the patient showed signs of a fever higher than $38^{\circ} \mathrm{C}$, leukocyte presence in urine sediment and bacterial proliferation in urine or blood samples.

Patients with suspected acute prostatitis were hospitalized and treated with IV fluids and empirical antibiotics. There after, those patients were treated according to urine culture antibiogram.

The perioperative and postoperative data were compared between Group 1 (with previous prostatitis) and Group 2 (without previous prostatitis). There were no known cases of previous chronic bacterial prostatitis in Group 1 and Group 2.

The variables considered for evaluating perioperative outcomes were time to surgery, surgical time, estimated blood loss, perioperative complications and length of hospital stay. Time to surgery was calculated using the difference between the date of diagnosis on TRUS biopsy and the date of surgery. A positive surgical margin was considered for oncological outcomes. The severity of surgical complications was graded according to the modified Clavien system [14].

All patients received a confidential questionnaire about their urinary symptoms and sexual function. This questionnaire was derived from the ICS-male questionnaire [15]. The participants were requested to complete the questionnaire 12 months after the surgery. Continence was defined as no pad and/or no urinary leakage. Patients who reported no erections preoperatively and patients receiving postoperative radiotherapy or hormone therapy were excluded from the study. Potency was defined as the ability to achieve and maintain an erection that was suitable for sexual intercourse.

Continuous variables were reported as mean values (SD). Student's t-test or Mann-Whitney U test were used to compare continuous variables, whereas Pearson's Chi-square test was used to compare categorical variables. The Kolmogorov-Smirnov test was used to evaluate sample distribution. Statistical results were considered significant at a level of $p<0.05$. All statistical analyses were performed using SPSS software version 22 (SPSS Inc., Chicago, IL, USA, IBM $\left.{ }^{\circledast}\right)$.

\section{RESULTS}

A total number of 320 patients were included. There were 23 patients in Group 1 (7.2\%) and 297 patients in Group $2(92.8 \%)$. There was no difference in the mean age, BMI, D'Amico clinical stage, ASA score, mean time to surgery, mean total PSA and prostate sizes between these groups (Table 1).

Table 1 lists the baseline characteristics of the 320 included patients. In Group 1, the operative time, hospitalization and bladder catheterization time was statistically increased by $40 \mathrm{~min}, 1.9$ days, and 2.5 days, respectively $(\mathrm{p}<0.001, \mathrm{p}<0.001, \mathrm{p}=0.02)$ (Table 2). The positive margin rate was not significantly different between the two groups $(p=0.64)$

\section{Table 1. Demographic data}

\begin{tabular}{|c|c|c|c|}
\hline & Group 1 & Group 2 & $\mathrm{p}$ \\
\hline Patient (n) & 23 & 297 & \\
\hline Mean age (y) & $62.54 \pm 3.6$ & $61.28 \pm 2.1$ & 0.65 \\
\hline $\mathrm{BMI}\left(\mathrm{kg} / \mathrm{m}^{2}\right)$ & 25.38 & 26.22 & 0.70 \\
\hline Mean Total PSA (ng/ml) & $7.6 \pm 4.3$ & $8.01 \pm 4.8$ & 0.16 \\
\hline Mean prostate weight (g) & $48.9 \pm 24.7$ & $51.3 \pm 22.8$ & 0.26 \\
\hline \multicolumn{4}{|l|}{ ASA (\%) } \\
\hline 1 & 38.7 & 37.5 & 0.74 \\
\hline 2 & 24.5 & 25.2 & 0.81 \\
\hline 3 & 36.8 & 37.3 & 0.80 \\
\hline Mean time to surgery (days) & 84.8 & 78.5 & 0.10 \\
\hline \multicolumn{4}{|l|}{ Clinical stage (\%) } \\
\hline Low-risk & 43.3 & 43.5 & 0.75 \\
\hline Intermediate-risk & 48 & 47.8 & 0.80 \\
\hline High-risk & 8.7 & 8.7 & 0.90 \\
\hline Lymph node dissection (\%) & 23 & 21.8 & 0.72 \\
\hline
\end{tabular}

BMI - body mass index, ASA - American Society of Anesthesiologists 
CEnTRAL EUROPEAN JOURNAL OF UROLOGY

Table 2. Perioperative, oncological and functional outcomes

\begin{tabular}{|c|c|c|c|}
\hline & Group 1 & Group 2 & $\mathrm{p}$ \\
\hline Surgical time (min) & $248 \pm 36$ & $208 \pm 31$ & $<0.001$ \\
\hline Mean hospital stay (d) & $8.4 \pm 3.8$ & $6.5 \pm 2.8$ & $<0.001$ \\
\hline Mean catheter time $(\mathrm{d})$ & $13.9 \pm 3.4$ & $11.4 \pm 4.1$ & 0.02 \\
\hline Blood transfusion (\%) & 41.2 & 37.9 & 0.16 \\
\hline Positive surgical margins & 25.2 & 24.7 & 0.64 \\
\hline $\begin{array}{l}\text { The number of complications } \\
\text { with Clavien }>2\end{array}$ & $6(26 \%)$ & $36(12 \%)$ & 0.02 \\
\hline \multicolumn{4}{|l|}{ Complication type (Clavien $>2$ ) } \\
\hline Urinary fistula & 1 & 11 & \\
\hline Sepsis & 1 & 8 & \\
\hline Lymphocele & 1 & 12 & \\
\hline CPR & 1 & 1 & \\
\hline Rectal injury & 2 & 4 & \\
\hline Nerve sparing (\%) & 46.5 & 76.9 & 0.02 \\
\hline $\begin{array}{l}\text { Potency with NVB } \\
\text { preservation (\%) }\end{array}$ & 63.1 & 68.9 & 0.57 \\
\hline Continence rate (\%) & 88.9 & 94.8 & 0.61 \\
\hline
\end{tabular}

CPR - cardiopulmonary resuscitation, NVB - neurovascular bundle

(Table 2). A statistically significant difference was observed between the two groups for complications. Complications with Clavien $>2$ (urinary fistula, sepsis, lymphocele, cardiopulmonary resuscitation (CPR), rectal injury) occurred in $26 \%$ of Group 1 and $12 \%$ of Group $2(\mathrm{p}=0.02)$ (Table 2$)$. Neurovascular bundle (NVB) preservation ratio was statistically higher in Group 2 (76.9\%) compared to Group 1 $(46.5 \%)(\mathrm{p}=0.02)($ Table 2$)$.

The continence rate was $88.9 \%$ in Group 1 and $94.8 \%$ in Group 2, respectively, 12 months after the surgery $(\mathrm{p}=0.57)$, whereas the potency rate with neurovascular bundle preservation was $63.1 \%$ and $68.9 \%$, respectively $(\mathrm{p}=0.61)$ (Table 2$)$.

\section{DISCUSSION}

TRUS-TRBx is generally accepted as a standard procedure for diagnosing PCa. Moreover, direct bacterial seeding from a prostate biopsy is still the most common cause of ABP [16].

Although the incidence of TRUS-TRBx-induced acute prostatitis is low, it is a typically serious complication when it does occur. Despite the use of prophylactic antibiotics, some patients may develop febrile infections or sepsis with a reported incidence of $0-3.5 \%$ after the procedure. The incidence of ABP because of TRBx has increased in the last 10 years, possibly because of an increase in drug-resistant strains of bacteria $[11,12,13]$.

The impact of prostate biopsies and their possible complications on prostate-surrounding tissues has been an important matter of study. Reports have suggested that TRUS prostate biopsies cause local tissue trauma because of direct damage or due to eventual association to infection complications. Both of these events can result in inflammation and lead to local fibrosis and scar tissue formation $[17,18]$.

We did not observe any statistically significant difference between the two groups for blood loss; however, the operative time, hospitalization and bladder catheterization times were longer for patients who had previous transrectal prostate biopsy-related acute prostatitis history. In our experience, the operative difficulties were primarily encountered during resection of the posterior part of the bladder neck, as well as when starting dissection of the posterior plane of the prostate in patients who had previous prostatitis history.

These technical difficulties did not seem to influence the oncologic outcomes after RP, as shown by the overall positive surgical margin rate. In fact, we observed an increased surgical complication rate in patients who had previous prostatitis history.

Menard et al. suggested that waiting for at least three months between TURP and RP reduced the effect of postoperative inflammation [19]. The proposed hypothesis is capsular perforation during TURP and extravasation of the irrigation fluid, which causes periprostatic fibrosis [20]. However, the local inflammatory effect of the TRUS biopsy is well established. It is currently recommended to wait at least between 4 and 6 weeks before performing radical prostatectomy after biopsy-related prostatitis. In fact, to minimize potential risks of surgical complications, application of longer intervals ( $>6$ weeks) between biopsy and surgery may be advisable. However, further studies are necessary to confirm this suggestion.

Although the demographic characteristics of these groups were similar, NVBs was technically feasible in only $46.5 \%$ of patients in Group 1 and $76.9 \%$ in Group 2 according to our study.

In terms of functional results, we observed slightly better results for Group 2 but without statistically significant differences. To our knowledge, this is the first study that demonstrates the effect of biopsy-related prostatitis on the surgical and functional outcomes of radical prostatectomy.

\section{CONCLUSIONS}

Radical retropubic prostatectomy can be performed in patients with prostatitis history without compromising oncologic results. However, patients should be informed that this procedure is associated with 
worse intraoperative and postoperative outcomes. Although the neurovascular bundle preservation is technically more difficult, potency and urinary continence rates were not affected by previous prostatitis history according to our study. How- ever, further studies are still necessary to confirm these results.

\section{CONFLICTS OF INTEREST}

The authors declare no conflicts of interest.

\section{References}

1. Krieger JN, Nyberg L Jr, Nickel JC. NIH consensus definition and classification of prostatitis. JAMA. 1999; 282: 236-237.

2. Millán-Rodríguez F, Palou J, Bujons-Tur A, et al. Acute bacterial prostatitis: two different sub-categories according to a previous manipulation of the lower urinary tract. World J Urol. 2006; 24: 45-50.

3. Etienne $\mathrm{M}$, Chavanet $\mathrm{P}$, Sibert $\mathrm{L}$, et al. Acute bacterial prostatitis: heterogeneity in diagnostic criteria and management. Retrospective multicentric analysis of 371 patients diagnosed with acute prostatitis. BMC Infect Dis. 2008; 8: 12.

4. Yoon BI, Kim S, Han DS, et al. Acute bacterial prostatitis: how to preventand manage chronic infection? J Infect Chemother. 2012; 18: 444-450.

5. Kim SH, Ha US, Yoon BI, et al. Microbiological and clinical characteristics in acute bacterial prostatitis according to lower urinary tract manipulation procedure. J Infect Chemother. 2014; 20: 38-42.

6. Nagy V, Kubej D. Acute bacterial prostatitis in humans: current microbiological spectrum, sensitivity to antibiotics and clinical findings. Urol Int. 2012; 89: 445-450.

7. Ha US, Kim ME, Kim CS, et al. Acute bacterial prostatitis in Korea: clinical outcome, including symptoms, management, microbiology and course of disease. Int I Antimicrob Agents. 2008; 31 (Suppl 1): S96-S101.
8. Ramakrishnan K, Salinas RC. Prostatitis: acute and chronic. Prim Care. 2010; 37: 547-563.

9. Campeggi A, Ouzaid I, Xylinas E, et al. Acute bacterial prostatitis after transrectal ultrasound-guided prostate biopsy: Epidemiological, bacteria and treatment patterns from a 4- ear prospective study. Int J Urol. 2014; 21: 152-155.

10. Grummet JP, Weerakoon M, Huang S, et al. Sepsis and 'superbugs': should we favour the transperineal over the transrectal approach for prostate biopsy? BJU Int. 2014; 114: 384-388.

11. Oh MM, Chae JY, Kim JW, et al. Positive culture for extended-spectrum $\beta$-lactamase during acute prostatitis after prostate biopsy is a risk factor for progression to chronic prostatitis. Urology. 2013; 81: 1209-1212.

12. Nam RK, Saskin R, Lee $Y$, et al. Increasing hospital admission rates for urological complications after transrectal ultrasound guided prostate biopsy. J Urol. 2013; 189: S12-17.

13. Shigemura K, Tanaka K, Adachi M, Yamashita M, Arakawa S, Fujisawa M. Chronological changeof antibiotic use and antibiotic resistance in Escherichia coli causing urinary tract infections. J Infect Chemoth. 2011; 17: 646-651.

14. Clavien PA, Barkun J, de Oliveira ML, et al. The Clavien-Dindo classification of surgical complications: five-year experience. Ann Surg. 2009; 250: 187-196.

15. Bates TS, Wright MPJ, Gillatt DA, et al. Prevalence and impact of incontinence and impotence following total prostatectomy assessed anonymously by the ICS-male questionnaire. Eur Urol. 1998; 33: 165-169.

16. Ehdaie, B, Vertosick E, Spaliviero M. The impact of repeat biopsies on infectious complications in men with prostate cancer on active surveillance. J Urol. 2014; 191: 660-664.

17. Anderson CB, Tin AL, Sjoberg DD, et al. Association between number of prostate biopsies and patient-reported functional outcomes after radical prostatectomy: implications for active surveillance protocols. BJU Int. 2016; 117: E46-51.

18. Glass, AS, Porten SP, Bonham M, et al. Active surveillance: does serial prostate biopsy increase histological inflammation? Prostate Cancer Prostatic Dis. 2013; 16: 165-169.

19. Menard J, de la Taille A, Hoznek A, et al. Laparoscopic radical prostatectomy after transurethral resection of the prostate: surgical and functional outcomes. Urology. 2008; 72: 593-597.

20. Ramon J, Rossignol G, Leandri P, Gautier JR. Morbidity of radical retropubic prostatectomy following previous prostate resection. J Surg Oncol. 1994; 55: 14-19. 